\title{
AIR TEMPERATURE CONTROL SYSTEM IN A BUILDING ON THE BASIS OF MATHEMATICAL MODELLING
}

\author{
Aleksandr Pilipenko*, Sergei Petrov \\ Orel State University named after I.S.Turgenev, 302020, Oryol, Russia
}

\begin{abstract}
In the article the authors solve a crucial objective of reducing the cost of heating services through the introduction of a system, controlling boilers and heating devices, based on modelling of the building and predicting heating systems functioning and operation. The authors describe the method of mathematical modelling of heating systems of the building and represent the developed mathematical models, pledged and installed into the developed automated system. The authors have offered an automated system of dispatch control of the boilers with the elements of computer simulation and modelling.
\end{abstract}

\section{Introduction}

Development of intelligent (intellectual) systems of management and control of the buildings and nonstationary technological processes is an urgent and relevant objective now. One of the most common nonstationary processes in buildings is the process of air temperature regulation with an account of heat losses. In this regard, the development of the automated control systems of air temperature in the building with elements of forecasting, based on mathematical modelling is a promising and prospective research area.

The existing dependences for transfer functions of the links of the systems under consideration and research are not always convenient for complex integrated control models [1-3]. It is important to have a model, that would be able to manage and control temperature of the building by changing the coolant flow (consumption of a heat-transfer agent) and its temperature. Assuming that the heating system is established and stabilized, and values of air temperature in different rooms are similar, it is useful to represent it in the form of a long pipe in order to develop a mathematical model of heating system (Figure 1), through which the heat transfer with $T(x, t)$ temperature, depending on $(x)$ distance and $(t)$ time flows.

\footnotetext{
* Corresponding author: a@pilipenko.info
} 


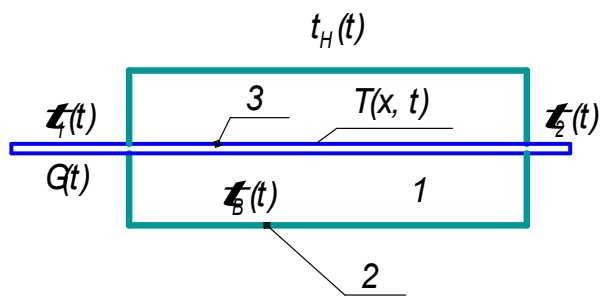

Fig. 1. The diagram, showing the principle scheme of a heated building and heating systems: 1 - denotes the heated building; 2 - denotes the external enclosures (rails) of the heated building; 3 - denotes the tube, which is equivalent to a heating system of the building.

The heating system is often treated as a set and range of parallel and consistently included pipelines and heating appliances; the latter can be represented by the length of the pipe, having larger section and the perimeter. It is anticipated that the area and perimeter of the living section, as well as pipeline length, which is equivalent to the heating system are defined with a help of experimental data on derived from the work of the system, i.e. the suggested model can be configured in relation to a real running system of heating.

\section{Mathematical model}

We get the differential equation (1) in partial equations with boundary and initial conditions (2) from the condition of thermal balance of the pipe after transformations.

$$
\begin{gathered}
\mathrm{cG}(\mathrm{t}) \frac{\partial \mathrm{T}}{\partial \mathrm{x}}+\mathrm{cS} \frac{\partial \mathrm{T}}{\partial \mathrm{t}}+\mathrm{kfT}=\mathrm{kfT}_{\mathrm{B}}, \\
\mathrm{T}(0, \mathrm{t})=\tau_{1}(\mathrm{t}) ; \mathrm{T}(\mathrm{x}, 0)=\mathrm{T}_{0}(\mathrm{x}),
\end{gathered}
$$

where $\mathrm{c}$ is the volumetric heat capacity of water, joules $/\left(\mathrm{m}^{3} \times \mathrm{K}\right) ; \mathrm{G}(\mathrm{t})$ denotes the heat carrier (coolant channel) flow (consumption) rate in the heating system, $\mathrm{m}^{3} / \mathrm{h} ; \mathrm{S}, \mathrm{f}$ denote the area $\left(\mathrm{m}^{2}\right)$ and the perimeter $(\mathrm{m})$ of the living section of the equivalent pipe respectively; $\mathrm{k}$ is the coefficient of heat transfer through the walls of the pipe, watt $/\left(\mathrm{m}^{2} \times{ }^{\circ} \mathrm{C}\right) ; \mathrm{T}_{\mathrm{B}}(\mathrm{t})$ is the average temperature of internal air, ${ }^{\circ} \mathrm{C} ; \tau_{1}(\mathrm{t})$ denotes water temperature at the inlet of the heating system, ${ }^{\circ} \mathrm{C} ; \tau_{2}(\mathrm{t})$ is temperature of water at the outlet of the heating system (in the process of heading out of the system), ${ }^{\circ} \mathrm{C}$.

Applying direct and inverse Laplace transform [4], we can write down the solution to the task for semi-infinite pipe in the following form:

$$
\begin{aligned}
& \mathrm{T}(\mathrm{x}, \mathrm{t})=\exp (-\mathrm{kft} /(\mathrm{cS})) \mathrm{T}_{0}\left(\mathrm{x}-\mathrm{S}^{-1} \times\right. \\
& \times \int_{0}^{\mathrm{t}} \mathrm{G}(\varphi) \mathrm{d} \varphi+(\mathrm{kf} /(\mathrm{cS})) \cdot \int_{0}^{\mathrm{t}} \exp (-\mathrm{kf}(\mathrm{t}-\varphi) /(\mathrm{cS})) \cdot \mathrm{T}_{\mathrm{B}}(\varphi) \cdot 1\left(\mathrm{x}-\mathrm{S}^{-1}\right) \times \\
& \left.\times \int_{\varphi}^{\mathrm{t}} G(\theta) d \theta\right) d \varphi+\mathrm{S}^{-1} \cdot \int_{0}^{\mathrm{t}} \exp (-\mathrm{kf}(\mathrm{t}-\varphi) /(\mathrm{cS})) \cdot \mathrm{G}(\varphi) \tau_{1}(\varphi) \delta \cdot\left(\mathrm{x}-\mathrm{S}^{-1} \times\right. \\
& \left.\times \int_{\varphi}^{\mathrm{t}} G(\theta) d \theta\right) d \varphi \\
& \text { where } 1(\mathrm{x})=\left\{\begin{array}{l}
0, \mathrm{x} \leq 0 \\
1, \mathrm{x}>0
\end{array}\right.
\end{aligned}
$$


By means of replacing the $\mathrm{z}=\mathrm{x}-\mathrm{S}^{-1} \int_{\varphi}^{t} G(\theta) \mathrm{d} \theta$ variable we transform expression (3); let's take into consideration the fact, that when $\mathbf{t}$ are large enough, influence of initial conditions is missing, besides, we are interested in a limited range of values $\mathrm{x} \in(0, l)(\boldsymbol{l}$ denotes length of the equivalent pipe, $\mathrm{m}$ )

$$
\begin{aligned}
& \mathrm{T}(\mathrm{x}, \mathrm{t})=(\mathrm{kf} / \mathrm{c}) \cdot \int_{0}^{\mathrm{x}} \exp (-(\mathrm{kf} /(\mathrm{cS})) \cdot(\mathrm{t}-\varphi(\mathrm{z}, \mathrm{x}, \mathrm{t}))) \\
& \mathrm{T}_{\mathrm{B}}(\varphi(\mathrm{z}, \mathrm{x}, \mathrm{t})) / \mathrm{G}(\varphi(\mathrm{z}, \mathrm{x}, \mathrm{t})) \mathrm{dz}+\exp (-(\mathrm{kf} /(\mathrm{cS}))(\mathrm{t}-\varphi(0, \mathrm{x}, \mathrm{t}))) \cdot \tau_{1}(\varphi(0, \mathrm{x}, \mathrm{t})),
\end{aligned}
$$

where $\varphi(z, x, t)$ and $\varphi(0, \mathrm{x}, \mathrm{t})$ are the roots of equations respectively $\mathrm{x}-\mathrm{S}^{-1} \cdot \int_{\varphi}^{\mathrm{t}} \mathrm{G}(\theta) \mathrm{d} \theta=\mathrm{z} \quad$ и $\quad \mathrm{x}=\mathrm{S}^{-1} \cdot \int_{\varphi}^{\mathrm{t}} \mathrm{G}(\theta) \mathrm{d} \theta$

In practice, measurement of the heating systems parameters is done discretely. Let's set in the settings that all values are measured in the moments of time $(t=n h)$, where $\mathrm{h}$ is the sampling interval. Controlling values are also measured in these moments, and we consider that the inlet temperature of straight flowing water varies between the neighboring time points $n h,(n+1) h$, linearly, and consumption (flow) in this interval remains constant and unchangeable and equal to $\mathrm{G}(\mathrm{nh})$. The sampling interval $(h)$ is usually assumed to be equal to several hours (from 1 to $6 h$ ) because of the large heat storage capacity (heat accumulation) of buildings. Time of the passage of water through the heating system ranges from 10 to $30 \mathrm{~min}$; whence, we may come to the conclusion that $\mathrm{Sl} / \mathrm{G}<\mathrm{h}$. Taking into consideration the suggestions and formulae, represented above, we obtain an expression for the $\varphi=n h-S(l-z) / G((n-1) h)$ value. Thus, we write the formula (4) for return water, i.e. when $\mathrm{x}=(1)$

$$
\begin{aligned}
& \left.\tau_{2}(\mathrm{nh})=\mathrm{T}(l, \mathrm{nh})=(\mathrm{kf} / \mathrm{c}) \cdot \int_{0}^{1} \exp (-\mathrm{kf}(l-\mathrm{z}) / \mathrm{cG}((\mathrm{n}-1) \mathrm{h}))\right) \times \\
& \times \mathrm{T}_{\mathrm{B}}(\mathrm{nh}-\mathrm{S}(l-\mathrm{z}) / \mathrm{G}((\mathrm{n}-1) \mathrm{h})) \mathrm{dz}+\exp (-\mathrm{kfl} /(\mathrm{cG}((\mathrm{n}-1) \mathrm{h}))) \tau_{1}(\mathrm{nh}-\mathrm{S} l / \mathrm{G}((\mathrm{n}-1) \mathrm{h}))
\end{aligned}
$$

As the $\mathrm{T}_{\mathrm{B}}(\mathrm{nh}-\mathrm{S}(l-\mathrm{z}) / \mathrm{G}((\mathrm{n}-1) \mathrm{h}))$ and $\tau_{1}(\mathrm{nh}-\mathrm{S} l / \mathrm{G}((\mathrm{n}-1) \mathrm{h}))$ values are not measured, so, we get them by means of linear interpolation in the interval ((n-1) h, nh), of the known values $\mathrm{T}_{B}((\mathrm{n}-1) \mathrm{h}), \mathrm{T}_{\mathbf{B}}(\mathrm{nh}) \tau_{1}((\mathrm{n}-1) \mathrm{h}), \tau_{1}(\mathrm{nh})$. Taking into account the last of the ratios (5), after evaluating the integrals, we get the following expressions:

$$
\begin{aligned}
& \tau_{2}(\mathrm{nh})=\mathrm{T}_{\mathrm{B}}(\mathrm{nh})(1-\exp (-\mathrm{kf} l /(\mathrm{cG}((\mathrm{n}-1) \mathrm{h}))))+\left(\mathrm{T}_{\mathrm{B}}((\mathrm{n}-1) \mathrm{h})-\right. \\
& -\mathrm{T}_{\mathrm{B}}(\mathrm{nh})(1-\exp (-\mathrm{kf} l /(\mathrm{cG}((\mathrm{n}-1) \mathrm{h})))) \mathrm{cS} /(\mathrm{hkf})-\left(\mathrm{T}_{\mathrm{B}}((\mathrm{n}-1) \mathrm{h})-\mathrm{T}_{\mathrm{B}}(\mathrm{nh})\right) \times \\
& \times \exp (-\mathrm{kf} l /(\mathrm{cG}((\mathrm{n}-1) \mathrm{h}))) \mathrm{S} / /(\mathrm{hG}((\mathrm{n}-1) \mathrm{h}))+\exp (-\mathrm{kf} l /(\mathrm{cG}((\mathrm{n}-1) \mathrm{h}))) \times \\
& \times\left(\tau_{1}(\mathrm{nh})+\left(\tau_{1}((\mathrm{n}-1) \mathrm{h})-\tau_{1}(\mathrm{nh})\right) \mathrm{S} / /(\mathrm{hG}((\mathrm{n}-1) \mathrm{h}))\right)
\end{aligned}
$$

In order to predict the air temperature inside the building we have used (applied) the results, obtained in [5], where the building has been seen as a single container link and impacts on the building have been approximated by the zero degree splines. For a particular point (moment) in time $((\mathrm{n}+1) / \mathrm{h})$ we have the following equation $(7)$ :

$$
\begin{aligned}
& T_{B}((n+1) h)-T_{H}((n+1) h)-Q((n+1) h) /\left(q_{0} V\right)= \\
& \left.=\exp (-h / \beta / \beta)_{B}(n h)-T_{H}(n h)-Q((n+1) h) /\left(q_{0} V\right)\right),
\end{aligned}
$$

where $\mathrm{T}_{\mathrm{H}}$ is temperature of external air, ${ }^{\circ} \mathrm{C}$; $\mathrm{Q}$ denotes the heat supply into the building joules/hour; $\mathrm{q}_{0}$ denotes the specific heat losses of the building, joules $/\left(\mathrm{m}^{3} \mathrm{~h}^{\circ} \mathrm{C}\right)$; V is the volume of the building on the outer measurement, $\mathrm{m} 3 ; \beta$ denotes the coefficient of an 
accumulation. Let's write down the formula for the amount of heat, given (transmitted) to the building by the system of heating,

$$
Q(n h)=c G((n-1) h)\left(\tau_{1}(n h-S l / G((n-1) h))-\tau_{2}(n h)\right) .
$$

The argument of the $\tau_{1}$ value takes into account the transport delay of the coolant in the process of passing through the system of heating. By means of interpolating $\tau_{1}$ linearly let's substitute the expression for $Q((n+1) h)$ from formula (8) into formula (7), using beforehand the formula (6) for defining $\tau_{2}((n+1) h)$. In order to simplify the result we have introduced the following nomenclature (notations)

$$
\begin{aligned}
& A_{1}=(1-\exp (-h / \beta))(1-c S /(h k f)) c /\left(q_{0} V\right) ; \\
& A_{2}=(1-\exp (-h / \beta)) c S l /\left(q_{0} V h\right) ; \\
& A_{3}=\exp (-h / \beta) ; \\
& A_{4}=c(1-\exp (-h / \beta)) /\left(q_{0} V\right) ; \\
& A_{5}=c S /(h k f) ; \\
& A_{6}(n h)=S l /(h G(n h))
\end{aligned}
$$

If we take into consideration these notations, the formulae for defining $T_{B}((n+1) h)$ and $\tau_{2}((n+1) h)$ will get the following form:

$$
\begin{aligned}
& \tau_{\mathrm{B}}((\mathrm{n}+1) \mathrm{h})=\left\{1+\mathrm{A}_{1} \mathrm{G}(\mathrm{nh})(1-\exp (-\mathrm{kf} l /(\mathrm{cG}(\mathrm{nh}))))+\mathrm{A}_{2} \exp (-\mathrm{kf} l /(\mathrm{cG}(\mathrm{nh})))\right\}^{-1} \times \\
& \times\left\{\mathrm{T}_{\mathrm{B}}(\mathrm{nh})\left(\mathrm{A}_{3}-\left(\mathrm{A}_{4}-\mathrm{A}_{1}\right) \mathrm{G}(\mathrm{nh})(1-\exp (-\mathrm{kf} l /(\mathrm{cG}(\mathrm{nh}))))+\mathrm{A}_{2} \exp (-\mathrm{kf} l /(\mathrm{cG}(\mathrm{nh})))\right)+\right. \\
& +\mathrm{T}_{\mathrm{H}}((\mathrm{n}+1) \mathrm{h})-\mathrm{A}_{3} \mathrm{~T}_{\mathrm{H}}(\mathrm{nh})+\mathrm{A}_{4} \mathrm{G}(\mathrm{nh}) \tau_{1}((\mathrm{n}+1) \mathrm{h}) \times \\
& \left.\times(1-\exp (-\mathrm{kf} l /(\mathrm{cG}(\mathrm{nh}))))-\mathrm{A}_{2}(1-\exp (-\mathrm{kf} l /(\mathrm{cG}(\mathrm{nh}))))\left(\tau_{1}((\mathrm{n}+1) \mathrm{h})-\tau_{1}(\mathrm{nh})\right)\right\} ;
\end{aligned}
$$

$$
\begin{aligned}
& \tau_{2}((\mathrm{n}+1) \mathrm{h})=\mathrm{T}_{\mathrm{B}}((\mathrm{n}+1) \mathrm{h})\left(1-\mathrm{A}_{5}+\left(\mathrm{A}_{6}(\mathrm{nh})+\mathrm{A}_{5}-1\right) \exp (-\mathrm{kf} l /(\mathrm{cG}(\mathrm{nh})))\right)+\mathrm{T}_{\mathrm{B}}(\mathrm{nh}) \times \\
& \times\left(\mathrm{A}_{5}-\left(\mathrm{A}_{5}+\mathrm{A}_{6}(\mathrm{nh})\right) \exp (-\mathrm{kf} l /(\mathrm{cG}(\mathrm{nh})))\right)+\exp (-\mathrm{kf} l /(\mathrm{cG}(\mathrm{nh})))\left(\tau_{1}((\mathrm{n}+1) \mathrm{h})+\right. \\
& +\left(\tau_{1}(\mathrm{nh})-\tau_{2}((\mathrm{n}+1) \mathrm{h})\right) \mathrm{A}_{6}(\mathrm{nh}) .
\end{aligned}
$$

Formulae (9), (10) predetermine the connection between $\tau_{2}, \tau_{1}, G, T_{B}, T_{H}$ in the dynamic regime (mode). As $\mathrm{T}_{\mathrm{H}}$ we should use and take the given above temperature of external air, taking into account both fast and slow heat loss, as well as the influence of wind and solar radiation $/ 2 /$. (9).

In the stationary mode we can get the known dependences [1, 2] out of expressions (8),

$$
\begin{aligned}
& \left(\tau_{2}-T_{B}\right) /\left(\tau_{1}-T_{B}\right)=\exp (-k f l /(c G)), \\
& q_{0} V\left(T_{B}-T_{H}\right)=c G\left(\tau_{1}-\tau_{2}\right) .
\end{aligned}
$$

Dependences (11), (12) can be used in order to define the initial approximation of values $k \mathrm{fl} / \mathrm{c}$ and $q_{0} \mathrm{~V} / \mathrm{c}$ in accordance with experimental data in stationary conditions. One must use the step-by-step approach (method). At each step magnitudes $\mathrm{k}, \beta, q_{0}$ can be adjusted and adopted to the changing operating conditions.

\section{System of control}

For the realization of the automatic control system with computer modelling LabVIEW graphical programming medium and cRIO controller from National Instruments have been 
chosen [6]. The advantage of using the LabVIEW graphical programming language in modelling is in the presence of functions (virtual appliances and gadgets), allowing and helping to solve differential equations in the period of time close to real time, by applying Runge Kutta method: Second order, as well as Laplace method.

The developed automated system consists of the hardware-software complex on the basis of cRIO (Figure 2), installed in the residential building and on the lower level of the boilers, as well as of the dispatching control panel (Figure 3), which is installed on distribution stations and boilers.

The work of lower-level automated control system comes to fulfilling two basic functions, such as: PID-regulation in accordance with the manually set values of the operator from the dispatching console; and regulation in a close to real time mode according to the specified database signs, based on the results of comparison of the data of simulations and modelling, as well as specific information from the sensors.

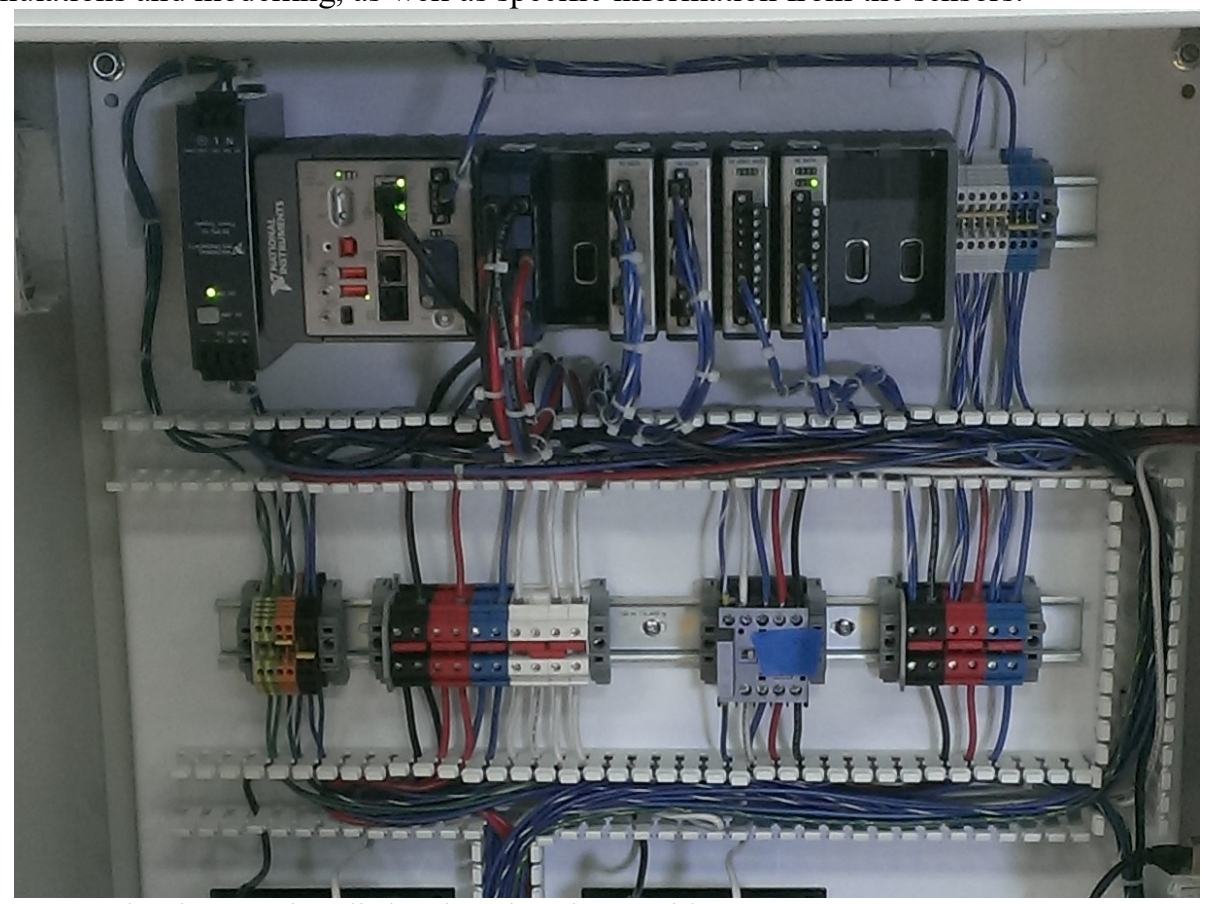

Fig. 2. Low-level system installation, based on the NI with RIO. 


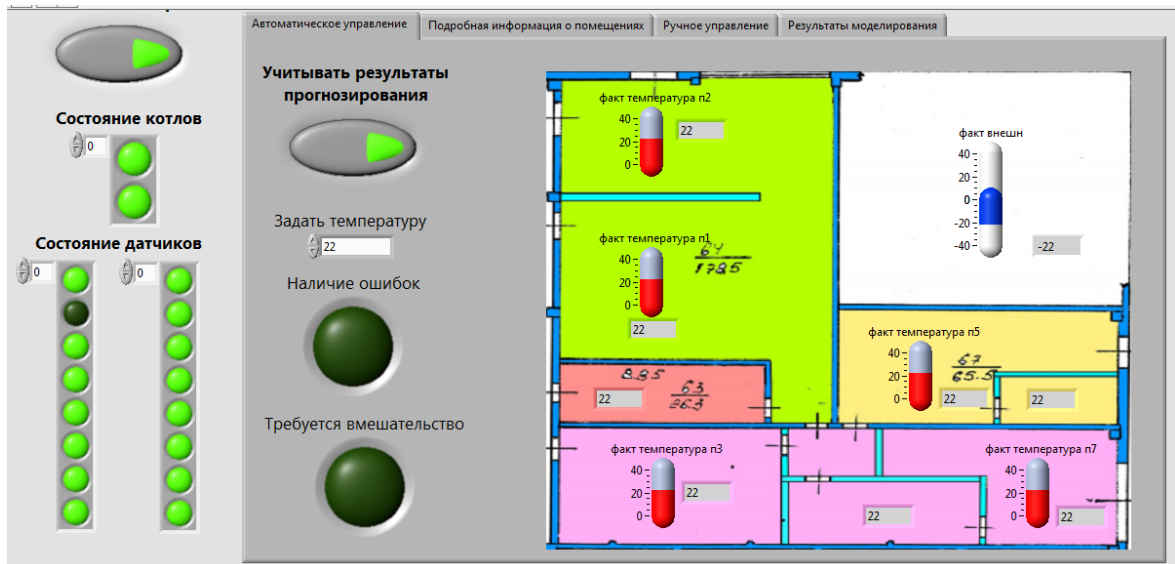

Fig.3.The screenshot of dispatching control panel.

\section{Conclusion}

The automated system has a number of unique features:

1. An account of the amount of heat, transmitted to the building, and comparison of actual values with the results of the simulations and modelling, which allows us to track various inclusions into the pipeline and/or change of the heating system design.

2. Prediction and forecasting of air temperature in the building on the basis of the results of computer simulations and modelling, which helps to increase accuracy of control and regulation and reduce air temperature fluctuations, as well as improve energy efficiency of functioning and work of the boiler.

3. An account, simulation and modelling of water temperature at the inlet and outlet of the heated room, assisting us in taking into account the actual (real) amount of consumed heat and correcting the cost of services, providing heating of the buildings.

The proposed method of modelling is applicable in the context of dispatching control of heating of separate buildings, as well as the district and area of heating as a whole. In the process of using it we may control the release of heat, provided not only to the private houses, dwellings and blocks of flats, but also to the public buildings, with a help of software. The use of the developed system allows us not only to make the house "Smart", but also to perform automation of boiler systems with an integration of the lower and upper levels with the functions of the manual and remote control of the heating systems of the building and boilers. Various tests and experiments show that the introduction of such a system helps us to reduce the cost of services of heating and increase the quality of control and regulation of boilers.

\section{References}

[1] Analysis and synthesis of control systems of thermal energy transfer process in the cogeneration system of central heating, Monograph, eds. PhD, Professor in Technical Sciences Susdalzev A.I. (Publishing House "Orlik \& K", Orel, 2009)

[2] P. Thota, B. Krauskopf, M. Lowenberg, Nonlinear Dynamics 57, 455(2009)

[3] C. Howcrof, B. Krauskopf, M. Lowenberg, S. Neild, SIAM Journal on applied dynamical systems 12, 1181 (2013)

[4] A.P. Hiwarekar, International Journal of Mathematical Archive 3/3, 1193 (2012) 
[5] Automation of cogeneration heat supply systems with distributed peak loads, Monograph, eds. PhD, Professor in Technical Sciences Susdalzev A.I. (Mashinostroenie, Moscow, 2007)

[6] A. Y. Nikiforov, P. K. Skorobogatov, A. N. Egorov, D. V. Gromov, Russian Microelectronics 43(2), 133 (2014) doi: 10.1134/S1063739714020073. 